\title{
Hereditary and Acquired Complement Component 1 Esterase Inhibitor Deficiency: A Review for the Hematologist
}

\author{
Marco Cicardi ${ }^{a}$ Douglas T. Johnston ${ }^{b}$

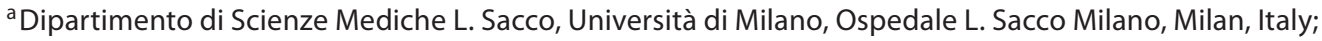 \\ ${ }^{\mathrm{b}}$ Allergy Partners of the Upstate, Greenville, S.C., USA
}

\section{Key Words}

Hereditary angioedema $\cdot$ Complement component 1

esterase inhibitor $\cdot$ Bradykinin

\begin{abstract}
Hereditary angioedema (HAE), a rare autosomal dominant disorder, was first described in the late 19th century. The disease remained poorly understood and without therapeutic options until the latter half of the 20th century. Advances in the understanding of immunologic and hematologic pathways have shed light on $\mathrm{HAE}$, a disease characterized by painful and unpredictable recurrent attacks of nonpitting edema without urticaria. Recognition that a deficiency of complement component 1 (C1) esterase inhibitor leads to overproduction of vasoactive kinins that cause angioedema paved the way for the development of early treatments. Increased understanding of the role of bradykinin in hereditary and acquired forms of $\mathrm{C} 1$ esterase inhibitor deficiency has led to the development of more targeted treatments for this painful, debilitating and potentially life-threatening disease.

Copyright $\odot 2012$ S. Karger AG, Basel
\end{abstract}

\section{Introduction}

Descriptions of hereditary angioedema (HAE) first appeared in the medical literature in the 1880 s $[1,2]$, but the underlying disorder affecting the inhibitor of the activated first component of complement, or $\mathrm{C} 1$ esterase inhibitor (C1-INH), was not identified until the 1960s [3]. C1-INH deficiency allows the activation of both the complement and coagulation cascades, ultimately resulting in the release of the vasoactive peptide bradykinin, which induces edema. The clinical manifestations of C1-INH deficiency, including recurrent episodes of nonpitting edema of the extremities, face, larynx, intestines and genitals, are a result of increased vascular permeability in subcutaneous and submucosal soft tissues $[4,5]$. The resultant swelling of the extremities, face and genitals may be debilitating and often interferes with normal activities $[6,7]$. Laryngeal and upper airway swelling is potentially life-threatening $[8,9]$. Abdominal pain accompanied by nausea, vomiting and/or diarrhea may occur secondary to intestinal edema; these complaints may mimic acute abdomen, leading to misdiagnosis and unnecessary surgical exploration. Together with the unpredictable nature and severity of the disease, these symptoms result in physical, emotional and economic burdens on patients and their families [10].

\section{KARGER \\ Fax +4161306 1234 \\ E-Mail karger@karger.ch}

www.karger.com
(C) 2012 S. Karger AG, Basel

0001-5792/12/1274-0208\$38.00/0

Accessible online at:

www.karger.com/aha
Marco Cicardi, MD

Dipartimento di Scienze Mediche L. Sacco

Università di Milano, Ospedale L. Sacco Milano

Via G.B. Grassi 74, IT-20157 Milano (Italy)

Tel.+39025031 9829, E-Mail marco.cicardi@unimi.it 


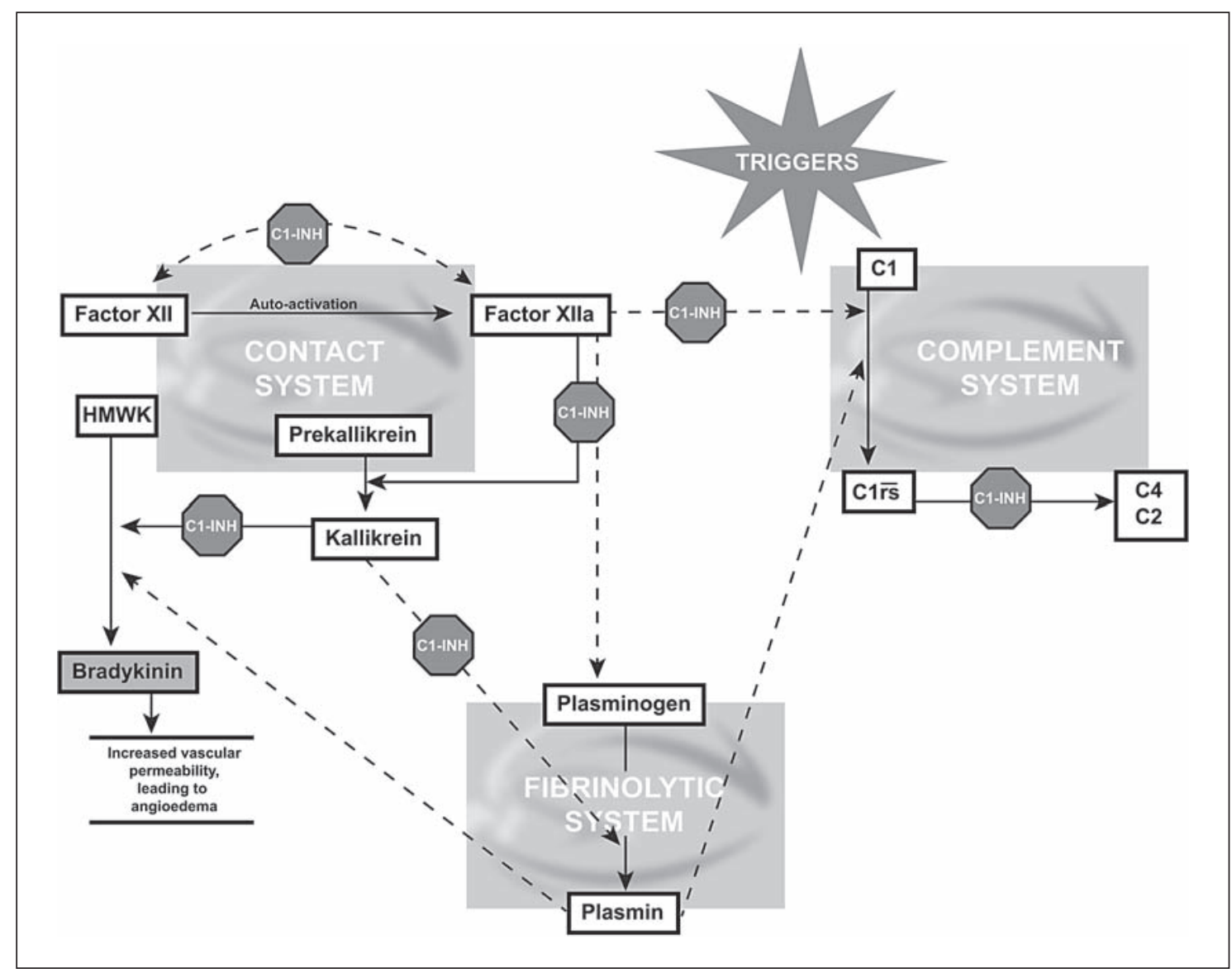

Fig. 1. Role of C1-INH in the contact, complement and fibrinolytic pathways. HMWK = High-molecular-weight kininogen.

With the increased understanding of the link between C1-INH, bradykinin release and angioedema symptoms, practical approaches to treating hereditary and acquired forms of angioedema have been developed. This review of the biochemistry, clinical characteristics and management of hereditary and acquired forms of C1-INH deficiency has been prompted by recent developments in the treatment of this disorder.

\section{C1 Inhibitor}

C1-INH is a glycosylated, $105-\mathrm{kD}$ serine protease inhibitor (serpin) that plays a regulatory role in the complement cascade, the contact system and the intrinsic coagulation cascade (fig. 1) [11]. Its major targets include the serine proteases $\mathrm{C} 1 \mathrm{~s}$ and $\mathrm{Clr}$ of the serum complement component $1(\mathrm{C} 1)$ complex, the mannan-binding lectin- associated serine proteases (MASPs), the contact system proteases (factor XIIa and plasma kallikrein) and other proteases including factor XIa, thrombin, plasmin and tissue-type plasminogen activator (tPA) [12].

Protease inactivation by serpins is accomplished by interaction of a serine at the active site on the protease with the reactive center of the serpin. Specifically, C1-INH and its target protease form a complex that permanently inactivates both the protease and the inhibitor, an action that C1-INH shares with other serpins [13].

\section{Role of C1-INH in the Complement, Contact and Coagulation Systems}

C1-INH regulates steps in the early activation of the classical complement cascade. The complement cascade is initiated when the $\mathrm{Clq}$ component of the $\mathrm{Cl}$ complex 
binds to the immunoglobulin-antigen complex formed during immune reactions. Once activated, the $\mathrm{C} 1 \mathrm{com}-$ plex cleaves the next 2 proteins in the cascade, complement component 4 (C4) and complement component 2 (C2) [6]. Subsequent activation of complement component 3 (C3) eventually leads to the production of inflammatory peptides associated with anaphylaxis and chemotaxis $[14,15]$. C1-INH prevents the initial activation and formation of $\mathrm{C} 1$ complex, thus blocking the production of downstream peptides. Deficiency of C1-INH results in loss of this regulatory influence, enabling inappropriate and uninhibited activation of the classical complement system [15].

Although it was named for its regulatory role in the complement system, the actions of C1-INH in the contact system are more important in the pathophysiology of HAE. The contact system consists of the substrate highmolecular-weight kininogen (HK) and the two zymogens prekallikrein and factor XII, which activate each other to form the enzymes kallikrein and activated factor XII (FXIIa), respectively [16]. In vitro, the system is activated after contact with negatively charged surfaces (hence the name), and the activation of prekallikrein to kallikrein depends on FXIIa [17]. In vivo, other pathways, independent of FXIIa, can activate prekallikrein on endothelial cells. For example, the membrane-expressed enzyme prolylcarboxypeptidase (PRCP) and/or the protein HSP90 can directly activate prekallikrein bound to endothelial cell surfaces $[18,19]$. A direct, C1-inhibitor-modulated enzymatic activity of prekallikrein has recently been suggested to act on angioedema pathogenesis [20].

The activation of the contact system results in blood coagulation and inflammation; however, its relevance in the coagulation cascade has been questioned because factor XII-, prekallikrein-, and HK-deficient patients do not suffer from bleeding disorders. FXIIa also leads to activation of the complement pathway.

Activation of the contact pathway produces FXIIa and plasma kallikrein, both of which are inhibited by C1-INH [12]. Exposure of factor XII to small quantities of FXIIa results in an increasing positive feedback loop, with FXIIa activating more factor XII. FXIIa then cleaves prekallikrein to produce kallikrein. Kallikrein cleaves HK to produce bradykinin, a potent vasodilator and inducer of vasopermeability, and cleaves factor XII, creating an efficient amplification loop. The cleavage of HK occurs at several points, enabling the release of the bradykinin nonapeptide, located inside the HK molecule, and other breakdown products (cleaved HK fragments) [21]. Bradykinin release is facilitated by the presence of plasmin [22]. Once generated, bradykinin is quickly degraded by peptidases human kininase I and kininase II, also known as carboxypeptidase $\mathrm{N}$ and angiotensin-converting enzyme (ACE), respectively. Other important kininases are aminopeptidase $\mathrm{P}$ and neutral endopeptidase. It is interesting to note that kininase II (i.e. ACE) not only degrades bradykinin but also activates angiotensin I to angiotensin II and thus represents an important link between the kinin system and the renin-angiotensin system [23]. In individuals with hereditary or acquired C1-INH deficiency, the rate of C1-INH depletion as it inactivates its target proteases and itself outstrips the pace of C1-INH production. The result is unregulated activation of several pathways and overproduction of bradykinin, leading to increased vascular permeability and severe edema [24]. Although there is still some debate as to whether all the angioedema-contributing components of these pathways have been identified $[25,26]$, there is a large body of evidence that supports the role of bradykinin in causing the characteristic tissue swelling of HAE [26-28].

Bradykinin is generated by 2 pathways: the plasma contact pathway previously described and a simpler system involving tissue kallikrein and its substrate, low-molecular-weight kininogen [26]. Tissue kallikrein is widely distributed in the body, including in the kidneys, blood vessels and central nervous system. Cleavage of low-molecular-weight kininogen by tissue kallikrein generates kallidin, which is converted to bradykinin by aminopeptidase. Bradykinin is a potent vasoactive peptide capable of causing vasodilation, increasing vascular permeability, producing hypotension, constricting uterine and gastrointestinal smooth muscle and dilating coronary and pulmonary vessels [29]. A variety of enzymes regulate bradykinin activity, chiefly through its degradation [28]. ACE is one such degradation enzyme that cleaves bradykinin into smaller molecules, thus deactivating it [30]. Angioedema has occurred in some susceptible individuals taking an ACE inhibitor to control their hypertension. In these individuals, ACE inhibition appears to result in an episodic accumulation of bradykinin and an increase in associated vasodilation and vasopermeability. Genetic polymorphisms associated with changes in the plasma levels of aminopeptidase seem to be a predisposing factor to ACE inhibitor-related angioedema [31].

The biological effects of bradykinin are exerted through activation of the bradykinin B2 receptor which is G-protein-coupled and generally expressed constitutively by vascular endothelial and smooth muscle cells [32]. Upon binding, the receptor is activated and trans- 
duces a signal cascade. Following activation, the receptor is desensitized, endocytosed and resensitized. In humans, there is another bradykinin receptor, named B1, which is closely related to the $\mathrm{B} 2$ receptor. It is activated by desArg(10)-kallidin or desArg(9)-bradykinin, which are metabolites of kallidin and bradykinin, respectively. The B1 receptor is induced following tissue injury or after treatment with bacterial endotoxins, such as lipopolysaccharide or cytokines. The search for kinin receptors culminated in the 1990s with the cloning of the rat B2 receptor CDNA by Jarnagin and coworkers. Three years later, the $\mathrm{B} 1$ receptor was also cloned. The targeted ablation of the genes encoding the $\mathrm{B} 2$ and $\mathrm{B} 1$ receptors in mice has helped to define more precisely the physiological and pathophysiological roles of kinin receptors.

\section{C1-INH Deficiency}

C1-INH deficiency may be inherited or acquired. HAE is due to mutations in the C1-INH gene (SERPING1) that result in deficiency or functional impairment of C1-INH. In most cases, these mutations are inherited in an autosomal dominant pattern, but they may arise de novo. There are 2 different types of hereditary deficiency of C1INH that are phenotypically identical and result in the symptoms of HAE $[15,30]$.

Type I HAE results from a deficiency in circulating C1-INH and accounts for approximately $85 \%$ of cases of HAE [30]. Clinical manifestations of type I HAE generally appear for the first time during the first 2 decades of life. Both the level and activity of C1-INH are low, as is the serum C4 level, but serum Clq level is typically normal.

Type II HAE results from production of dysfunctional forms of C1-INH and represents about 15\% of cases [13]. As in type I HAE, symptom onset generally occurs during the first 2 decades of life [30]. C1-INH levels may be normal or elevated, but the functional activity of the protein is diminished. The serum C4 level is decreased, and $\mathrm{Clq}$ levels are normal.

A hereditary form of angioedema has been described that is not caused by C1-INH deficiency or dysfunction $[8,33]$. HAE with normal C1-INH, which is clinically similar to types I and II HAE but etiologically unrelated to them, may be due to known mutations in the factor XII gene or to unknown genetic mutations. Both conditions are thought to result in overproduction of bradykinin. In some patients, HAE with normal C1-INH appears to be estrogen-sensitive. Compared to HAE types I and II, the first appearance of symptoms usually occurs later in life, after the second decade [30]. C1-INH level and activity, as well as $\mathrm{C} 4$ and $\mathrm{Clq}$ levels, have all been reported as normal in these cases.

Angioedema due to acquired C1-INH deficiency, frequently referred to as acquired angioedema (AAE), has also been reported rarely, usually in association with lymphoproliferative disorders or autoimmune, neoplastic, or infectious diseases [12]. The disease generally manifests in adulthood and is characterized by decreased activity of C1-INH, decreased but sometimes normal levels of $\mathrm{C} 1-\mathrm{INH}$ protein, decreased $\mathrm{C} 4$ and, frequently, decreased Clq.

\section{Hereditary C1-INH Deficiency (HAE Types I and II)}

\section{Epidemiology}

HAE is an inherited autosomal dominant disorder with an estimated prevalence between 1 in 50,000 to 1 in 10,000 people worldwide [30]. The precise prevalence is difficult to determine since diagnosis is often delayed for many years [33]. This delay, coupled with the rarity of the disease, places affected individuals at risk of death by asphyxiation from laryngeal swelling because physicians may mistakenly expect corticosteroids, epinephrine and antihistamines to be effective treatment options.

The prevalence of HAE types I and II does not appear to vary in different ethnic groups. Due to autosomal transmission, men and women are affected equally, although the disease course may be more severe in women.

\section{Pathogenesis}

SERPING1 is located on chromosome 11 [12]. The abnormalities found in SERPING1 in affected individuals are heterogeneous and involve various deletions or duplications distributed along the gene. More than 200 such mutations have been identified [34]. Type I HAE is associated with deletions or insertions of single or multiple nucleotides in SERPING1 that result in insufficient production of the C1-INH protein. Type II is typically associated with point mutations in the area of SERPING1 that codes for the reactive, protease-binding region of the C1INH protein. These mutations give rise to normal or even elevated levels of a dysfunctional C1-INH protein [30].

The autosomal dominant pattern of inheritance determines that a child of 1 affected parent has a $50 \%$ chance of acquiring the abnormal gene [24]. Approximately $75 \%$ of patients with HAE have a family history of the disease, whereas $25 \%$ of cases arise from spontaneous mutations. 
Once HAE is diagnosed, all first-order relatives of the affected individual should be tested to identify candidates for treatment and for genetic counseling.

Although some controversy remains regarding the identity and triggers of the vasoactive mediator underlying HAE, bradykinin remains the best and most consistently documented cause of the increased vascular permeability and extreme angioedema that characterize HAE $[12,35,36]$.

Bradykinin increases vasopermeability and initiates angioedema in vitro and in vivo, as seen in animal and human studies. Most importantly, increased bradykinin production has been demonstrated in patients with type I and type II HAE. Shoemaker et al. [37] compared kinin activity in plasma samples from HAE patients and normal controls. The HAE samples demonstrated kinin activity that, upon amino acid sequencing, proved to be bradykinin. Plasma samples collected during an attack or remission were found to increase the permeability of skin in a guinea pig skin model, and the vasopermeabilityinducing agent coeluted with bradykinin on reversephase high-performance liquid chromatography (HPLC). Further support for bradykinin as the primary mediator of swelling in HAE is found in murine studies conducted by Han et al. [38]. In these studies, vascular permeability was increased in C1-INH-deficient mice but not in mice deficient in both C1-INH and the bradykinin 2 receptor.

Plasma bradykinin concentrations, as measured by liquid-phase extraction, HPLC and radioimmunoassay, were found to be elevated in HAE and AAE patients in a study by Nussberger et al. [14]. The highest levels were measured in samples taken during attacks, and infusion of C1-INH reliably lowered bradykinin concentrations. Thus, several studies have established a causative link between C1-INH deficiency, increased bradykinin production, and development of the symptoms associated with HAE.

\section{Clinical Presentation}

Symptoms of HAE closely resemble a number of common disorders, leading to difficulties in the diagnosis and management of acute attacks. For example, the severe angioedema of the face and extremities characteristic of $\mathrm{HAE}$ is often mistaken for an allergic reaction and then treated with antihistamines, epinephrine and/or corticosteroids, all of which are ineffective for the treatment of HAE [12]. Abdominal edema, with its associated pain, distention, nausea, vomiting and diarrhea, may mimic the acute abdomen so closely as to prompt unnecessary surgical exploration [12, 39].
Symptoms include recurrent, nonpitting edema of subcutaneous and submucosal tissues, sometimes accompanied by a nonpruritic macular rash (erythema marginatum), but not urticaria [11]. An episode typically escalates in the first $24 \mathrm{~h}$ and subsides in the next $24-$ $72 \mathrm{~h}$ in milder cases or over 5 days in more severe cases, but the frequency, duration, and severity of attacks are variable [30]. Although most attacks do not have a specific trigger, an attack may follow trauma, emotional stress, medical procedures, menstruation, oral contraceptive use, infections or the use of an ACE inhibitor [8, 30]. Patients often experience some prodromal symptoms prior to an attack. In a survey of 49 patients, $87 \%$ reported having a prodromal symptom prior to their most recent HAE attack [40]. The most frequent prodromal symptoms reported in that survey were unusual fatigue (63\%), a rash on the arms or legs (47.8\%) and muscle aches (43.5\%). The frequency of attacks differs widely between individuals, ranging from twice weekly to almost never [33].

More than $90 \%$ of cases of HAE include swelling of the extremities involving the hands and feet $[7,24]$. Swollen joints and distortion of the soft tissues may interfere with a patient's ability to engage in activities such as walking, dressing, or even eating. Edema of the urogenital areas may arise from activities that place pressure on these areas, such as sexual intercourse, childbirth or horseback riding [24]. The discomfort of swelling of extremities, although not life-threatening, can interfere with normal activities and may require treatment.

Abdominal HAE attacks are the second most common manifestation of HAE and are associated with severe pain, vomiting, constipation, diarrhea and, in some cases, fluid loss (third spacing) leading to hypovolemic shock $[7,24]$. These symptoms are typically accompanied by a protuberant, tender abdomen, sometimes with rebound tenderness and guarding. This combination of symptoms and physical findings mimic surgical emergencies, resulting in unnecessary abdominal surgeries for these patients. The HAE patient with abdominal pain and hypotension is at risk of developing dehydration to the point of hypovolemic shock and should therefore be treated as an emergency case. Imaging studies may help differentiate between the need for surgery or aggressive fluid replacement and pain management until the edema subsides. Contrast-enhanced abdominal computed tomography (CT) may reveal intestinal wall and mucosal thickening consistent with edema, fluid accumulation in dilated small or large bowel loops and ascites [39]. Abdominal ultrasonography is also a useful tool to confirm 
the diagnosis of HAE during an acute abdominal attack. In a study of 22 acute abdominal HAE attacks severe enough to warrant hospital admission, abdominal ultrasound revealed thickening of the intestinal wall in $80 \%$ of the cases and the presence of free peritoneal fluid in all cases. Subsequent treatment of the HAE attack resulted in regression of all ultrasound abnormalities [41]. In another study of 11 acute abdominal HAE attacks, abdominal ultrasound performed during the attack revealed ascites and intestinal wall swelling in 7 of 11 patients, helping to confirm the diagnosis [42].

Facial swelling can be severely disfiguring, and up to one third of cases may spread to the larynx. Laryngeal edema may occur as a result of trauma to the oral cavity, such as dental surgery [8]. About $50 \%$ of patients will experience at least 1 episode of laryngeal edema during their lifetime, with the potential for airway obstruction $[24,30]$. Progression from onset of edema to laryngeal obstruction may range from minutes to hours [9]. Mortality from asphyxiation due to laryngeal edema may be as high as $40 \%$ [24]. Therefore, facial swelling and laryngeal edema should always be handled as an emergency.

\section{Diagnosis}

A history of recurrent nonpitting angioedema without urticaria, episodes of abdominal pain typically beginning in childhood or adolescence, and laryngeal edema, especially in the presence of a family history of similar occurrences, suggest HAE $[7,15]$. However, the lack of a family history of symptoms does not rule out HAE, as $25 \%$ of HAE cases are due to spontaneous mutations of SERPING1 [12]. A thorough medical and family history is needed for diagnosis when a case of unexplained angioedema is evaluated [43]. The medical history may reveal trauma, medication or other triggers as well as the frequency and typical severity of attacks [24].

Laboratory testing is indicated when HAE is suspected or if the family history is positive for recurrent edema; however, testing before the age of 1 year may yield falsenegative or false-positive results [43]. Measurements of C4, C1-INH antigenic protein, and C1-INH functional levels, if available, should be determined (fig. 2). In untreated HAE, a low serum $\mathrm{C} 4$ level demonstrates a high predictive value for $\mathrm{Cl}-\mathrm{INH}$ deficiency, thus serving as a good screening test [15]. Low serum C4 and C1-INH antigenic protein levels suggest a diagnosis of type I HAE. If $\mathrm{C} 4$ is low and C1-INH antigenic protein is normal but HAE is still suspected, a C1-INH functional assay should be performed by experienced laboratory personnel. Decreased C1-INH function in combination with low $\mathrm{C} 4$ and normal C1-INH antigenic protein indicates HAE type II. Normal C4 antigenic protein and C1-INH functional assays rule out HAE types I and II and may suggest another cause of swelling such as HAE with normal C1-INH or idiopathic angioedema $[15,43]$. If there is no family history and a late onset of symptoms (over 40 years of age) is reported, then AAE should be suspected. Clq testing confirms the diagnosis of AAE if the Clq level is low [43].

All tests should be done on fresh or freshly frozen serum samples [15]. C1-INH protein antigen and C4 testing are routine tests for most laboratories, but C1-INH functional assays are specialized tests and should be conducted only in reference laboratories experienced in sample handling [43]. C1-INH is normally low antigenically and functionally in children younger than 1 year, which makes test results difficult to interpret in this age group [15]. In addition, there are limited data on the reference ranges for these tests in very young children, and repeat testing may be needed to carefully assess results.

\section{Treatment of HAE}

Optimal management of HAE encompasses 3 approaches to patient care: (1) immediate therapy for an acute episode, (2) short-term prophylaxis before dental or surgical procedures and (3) routine prophylaxis to minimize the disruption of normal life that accompanies this disease $[10,44]$.

Acute attacks should be treated as soon as possible after onset. Although some guidelines have suggested that swelling limited to the extremities may not require treatment [12], these types of attacks may be especially debilitating, inhibiting the ability to walk, drive or write. Severe abdominal pain or laryngeal edema requires immediate attention. Treatment should be directed not only at addressing the C1-INH deficiency causing the swelling but also the necessary supportive care, such as pain medication for abdominal symptoms or intubation or tracheotomy to establish an open airway [44]. Rapid treatment after the onset of symptoms may shorten the time to symptom resolution, potentially limiting the development of more severe symptoms [45].

Dental procedures, medical interventions and surgery have all been known to trigger attacks of HAE [12]. Shortterm prophylaxis with appropriate agents should be considered before any such procedure in a patient with HAE, with the goal of preventing symptoms that may complicate recovery or further endanger the patient's health [46].

Long-term prophylaxis attempts to reduce the frequency of attacks and limit the impact of the disease on 
Fig. 2. Diagnostic algorithm for patients presenting with recurrent angioedema without urticaria. Adapted from Bowen et al. [43].

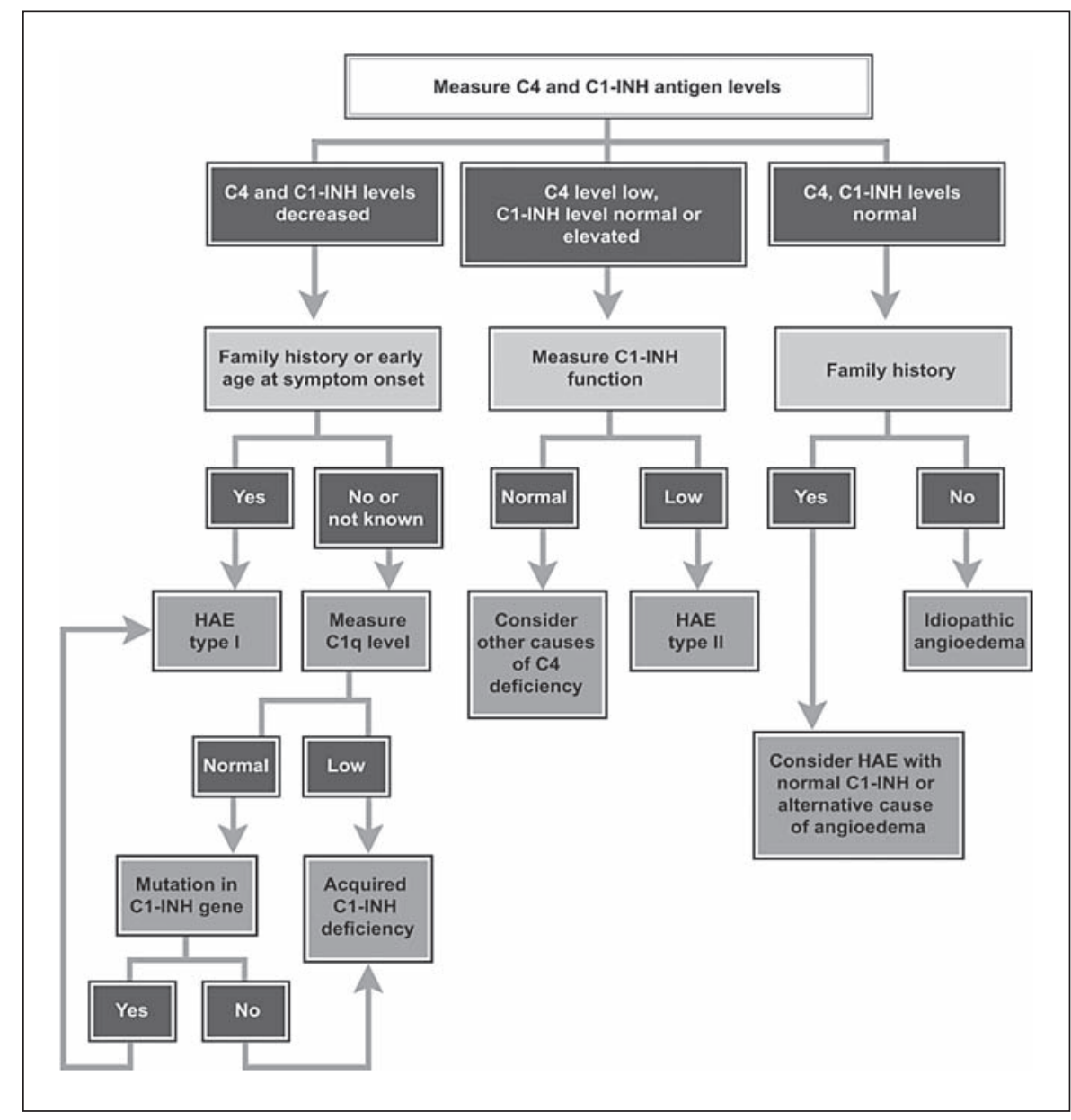

patients' lives [46]. HAE attacks typically take 3 days to subside, during which affected individuals may be absent from school or work and unable to participate in daily activities $[24,45]$.

Successful early acute treatment and long-term prevention of HAE attacks have the potential to mitigate morbidity and empower patients.

\section{Acute Treatment}

Few agents have been available for acute therapy of patients with C1-INH deficiency. Fresh frozen plasma was in use prior to the availability of these agents and is still used in some parts of the world; however, it has the potential to worsen an attack since it contains other components of the complement cascade and of the contact system in addition to C1-INH. Fresh frozen plasma should therefore be used with caution, particularly in emergency situations [44].
A plasma-derived, pasteurized $\mathrm{C} 1-\mathrm{INH}$ concentrate (pdC1-INH, marketed as Berinert ${ }^{\circledR}$ ) has been available in Germany for several decades. The manufacturer completed a mutual recognition procedure for the agent in 23 European countries in 2008, and pdC1-INH is currently approved for use in 28 countries worldwide [47, 48]. It has been approved in Europe for self-administration in appropriately trained patients. In a randomized, doubleblind, placebo-controlled trial, 125 patients with HAE were randomized to intravenous infusion of 10 or $20 \mathrm{U} /$ $\mathrm{kg}$ of pdC1-INH or placebo [49]. Compared with placebo, $20 \mathrm{U} / \mathrm{kg}$ of pdC1-INH significantly shortened the time to symptom relief. The most commonly reported adverse reactions were abdominal pain, diarrhea, headache, muscle spasms, nausea, pain, vomiting and subsequent HAE attack.

Products derived from human blood raise concerns about potential viral infection and dependence on an adequate donor blood supply. The introduction of a heat 
treatment step followed by chromatographic separation of a human-derived C1-INH product has prevented the transmission of viruses to date $[12,46]$; however, the problem of a donor blood supply still exists. Recombinant human C1-INH (rhC1-INH, marketed as Ruconest ${ }^{\circledR}$ ) is obtained from the milk of transgenic rabbits expressing the gene encoding for human C1-INH [50]. It was approved by the European Medicines Agency in 2010 for the treatment of acute angioedema attacks in adults with HAE. The recommended dose is $50 \mathrm{U} / \mathrm{kg}$ by intravenous injection for adults weighing up to $84 \mathrm{~kg}$. For those weighing $\geq 84 \mathrm{~kg}$, the recommended dose is $4,200 \mathrm{U}$ by intravenous injection. A recombinant rabbit-derived $\mathrm{C} 1-\mathrm{INH}$ product obviates the need for a donor blood supply and eliminates the possibility of viral transmission at the source; however, this process introduces the possibility of anaphylactic reactions in individuals allergic to rabbit dander or proteins. Thus, patients should be screened for rabbit sensitivity before starting therapy with rhC1-INH [50].

Icatibant (marketed as Firazyr ${ }^{\circledR}$ ) is a selective bradykinin B2 receptor antagonist available in Europe since 2008 and recently approved in the USA for the symptomatic treatment of acute attacks in adults with HAE [5153]. It is approved for self-administration in appropriately trained patients both in Europe and the USA. In a recent report of icatibant treatment of acute cutaneous or abdominal attacks in HAE patients, a total of 56 and 74 patients, respectively, were randomized in 2 doubleblind, multicenter trials. In the first trial, patients presenting with cutaneous or abdominal attacks of HAE received either icatibant $(30 \mathrm{mg})$ subcutaneously or placebo [51]. In the second trial, patients received either icatibant $(30 \mathrm{mg})$ subcutaneously or tranexamic acid ( 3 g) daily for 2 days. Icatibant significantly shortened the median time to the first improvement of symptoms in acute attacks of HAE compared to both tranexamic acid and placebo; however, the improvement in time to a clinically significant relief of symptoms was significant only in comparison to tranexamic acid. In a more recent phase III, double-blind, placebo-controlled trial of this agent, icatibant significantly reduced the median time to onset of symptom relief versus the placebo ( $2.0 \mathrm{vs.} 19.8 \mathrm{~h}$; $\mathrm{p}<0.001$ ) [52]. The most common adverse events were recurrent or worsening angioedema and injection-site reactions.

The newest product available in Europe for HAE is a nanofiltered C1-INH (nfC1-INH) product (marketed as Cinryze $^{\circledR}$ ) approved by the European Medicines Agency in June 2011 for use in adults and adolescents with HAE for routine prevention, preprocedural prevention and acute treatment of angioedema attacks [54]. The approval also includes a self-administration option for appropriately trained patients. This product was evaluated as acute treatment in a randomized, controlled trial of 68 subjects with moderate-to-severe HAE attacks involving the face, abdomen or genitalia. Subjects were randomly assigned to receive an intravenous 1,000- $\mathrm{U}$ injection of $\mathrm{nfC1}$-INH $(\mathrm{n}=35)$ or an equivalent volume of saline placebo $(\mathrm{n}=33)$ following a single HAE attack [55]. Patients were allowed to receive a second dose if symptoms did not improve within $60 \mathrm{~min}$. The median time to onset of unequivocal relief was $2 \mathrm{~h}$ in the nfC1-INH group versus $>4 \mathrm{~h}$ in the placebo group $(\mathrm{p}=0.02)$ [55]. Adverse events related to $\mathrm{Cl}-\mathrm{INH}$ administration were dizziness/anxiety (possibly related) and a rash at the injection site (definitely related).

Ecallantide is a plasma kallikrein inhibitor approved in the USA for the acute treatment of HAE; the product is not approved in the European Union. Ecallantide was studied in 2 randomized, double-blind, placebo-controlled trials involving 143 unique patients. Patients with 1 or more moderate-to-severe symptoms of HAE in any part of the body were randomized to receive placebo or ecallantide $(30 \mathrm{mg})$ subcutaneously. Ecallantide treatment reduced 2 measures of symptom severity, and fewer patients receiving ecallantide required additional medical intervention to treat unresolved symptoms within $24 \mathrm{~h} \mathrm{[56].} \mathrm{Ecallantide} \mathrm{was} \mathrm{administered} \mathrm{via} 3$ separate 10$\mathrm{mg}$ subcutaneous injections. Commonly reported adverse events included headache, nausea, diarrhea, pyrexia, injection-site reactions and nasopharyngitis for the patients receiving these injections. This medication carries a black box warning for the risk of anaphylaxis $(2.9 \%$ incidence in clinical trials) and must therefore be administered by a healthcare professional [56].

\section{Short-Term Prophylaxis}

Dental manipulation or surgery may precipitate an attack by inflicting tissue trauma [12, 43]. Patients planning to undergo such procedures may benefit from shortterm prophylaxis suitable for the type of expected trauma. The 2010 International Consensus Algorithm for the Diagnosis, Therapy and Management of Hereditary Angioedema [43] suggests that for major procedures and in patients with a high risk of attacks during procedures, prophylaxis should be considered. Unfortunately, no controlled studies support the efficacy of this approach with any particular treatment. The only product approved in Europe for preprocedural prophylaxis in adults 
and adolescents with HAE is nfC1-INH. The recommended dose, regardless of age or weight, is $1,000 \mathrm{U}$ administered within $24 \mathrm{~h}$ of a medical, dental or surgical procedure. Danazol has also been used for this purpose. Dosing has not been firmly established for the attenuated androgens when used for short-term prophylaxis, but some guidelines are suggested [43]. The recommended dose of danazol is $2.5-10 \mathrm{mg} / \mathrm{kg} /$ day up to a maximum of $600 \mathrm{mg}$ daily 5 days before and 2-5 days after the event. Stanozolol (4-6 mg/day) may be substituted. Androgens are preferred to antifibrinolytics for their efficacy in the short term. The suggested dose for tranexamic acid when it must be used is $25 \mathrm{mg} / \mathrm{kg}, 2-3$ times daily up to a maximum of 3-6 g daily orally, or $10 \mathrm{mg} / \mathrm{kg}$ 2-3 times daily intravenously (with adjustments for renal impairment). Fresh frozen plasma or solvent/detergenttreated plasma are alternatives only when C1-INH is not available for prophylaxis [43]. However, it should be noted that fresh frozen plasma contains complement components that have the potential to induce an HAE attack [30].

\section{Long-Term Prophylaxis}

Approved options for long-term prophylaxis against HAE attacks include attenuated androgens and nfC1INH. Some authors have suggested that prophylactic treatment be offered to patients who experience 1 or more acute attacks per month, but the high risk of mortality from laryngeal edema has been used to argue that all individuals with HAE are candidates for long-term prophylaxis in situations where effective acute treatment is not readily available [30].

In a double-blind, randomized crossover study in 9 HAE patients, 44 of 47 placebo courses ended with attacks, but during 46 danazol courses ( $600 \mathrm{mg} /$ day) only 1 attack occurred (2.2 vs. $93.6 \%, \mathrm{p}<0.001$ ) [57]. C1-INH levels increased 3- to 4-fold, and levels of the fourth component of complement (C4) increased 15-fold in danazoltreated patients [57]. In a similar study, methyltestosterone $(10 \mathrm{mg} /$ day) demonstrated a reduced HAE attack frequency of 4 attacks/46 months (vs. 19 attacks/11.8 months with a placebo) [58]. The efficacy of danazol and other androgen derivatives was further confirmed in observational studies using lower doses in order to reduce side effects [59-63]. It has been estimated that about one third of recognized HAE patients have been exposed to longterm prophylaxis with androgen derivatives in the last 35 years. This extensive experience permits the identification of side effects and facilitates the definition of a riskbenefit profile [64]. Androgen-related side effects are dose-dependent and commonly related to residual hormonal activity [65]. Given potential individual variability, doses of danazol $<200 \mathrm{mg} /$ day are usually well tolerated. Bork et al. [62] described weight gain, virilization, menstrual irregularities, headache, depression and/or liver adenomas in 93 of 118 patients treated with androgen derivatives for periods ranging between 2 months and 30 years. Because of these effects, 30 patients (25.4\%) discontinued therapy. Cicardi et al. [66] compared 36 HAE patients on androgen derivatives for a median of 125 months with $33 \mathrm{HAE}$ patients who did not receive such treatment. Arterial hypertension was present in $25 \%$ of patients in the treated group but only in $3 \%$ of the controls. Other side effects of chronic androgen use include liver enzyme elevation, liver tumors and dyslipidemia. Hepatocellular adenoma, carcinoma or focal nodular hyperplasia related to danazol treatment have been reported in several studies [67-71].

Although long-term prophylaxis with androgen derivatives has been shown to have adverse effects on lipid profile, it does not appear to be associated with increases in carotid intima-media thickness or prevalence of vascular disease in HAE patients [71-74].

The approval of nfC1-INH concentrate for routine prophylaxis of HAE introduced the first clinically tested alternative to attenuated androgens [54]. In a doubleblind study, $24 \mathrm{HAE}$ patients experiencing more than 1 attack per month were randomized to intravenous treatment of either 12 weeks of C1-INH followed by a 12-week placebo crossover or 12 weeks of placebo followed by a 12-week C1-INH crossover [55]. Patients served as their own controls. Patients were also allowed to receive rescue C1-INH treatment for any breakthrough attacks. When receiving $\mathrm{C} 1-\mathrm{INH}$, patients had approximately $50 \%$ fewer $\mathrm{HAE}$ attacks than when receiving placebo (primary end point). Patients on active therapy reported reduced attack severity and duration compared with the placebo period (secondary end points). The approved dose of this product in the prophylactic setting is $1,000 \mathrm{U}$ administered intravenously every 3-4 days, and it can be self-administered by patients after adequate training. Common adverse events reported were similar to placebo and included upper respiratory infection, sinusitis, rash and headache.

In clinical studies, the only common adverse reaction observed following nfC1-INH infusion was rash; characteristics were nonspecific but typically described as involving the upper extremities, chest, abdomen or injection site. None of the rashes were serious, and none led to discontinuation of nfC1-INH [75]. 


\section{Acquired C1-INH Deficiency}

\section{Epidemiology}

AAE, or more correctly, angioedema due to acquired C1-INH deficiency, is an extremely rare condition, often associated with lymphoproliferative and autoimmune disease [76, 77]. Cicardi and Zanichelli [76] estimate that its prevalence may be between 1:100,000 and 1:500,000, based on their experience of identifying $1 \mathrm{AAE}$ patient in every $10 \mathrm{HAE}$ patients. Since the condition is so often overlooked, the actual prevalence may be much higher.

\section{Pathology}

Similar to HAE, AAE syndrome is associated with a deficiency of C1-INH and recurrent angioedema symptoms [76]. In AAE, the deficiency arises from rapid depletion or consumption of C1-INH due to the presence of autoantibodies to C1-INH or to hyperactivation of the classic complement pathway. Lymphoma is often present in patients with AAE, although other lymphoproliferative disorders have also been reported in association with it. The observation of autoantibodies in the presence of lymphoma suggests to some researchers that AAE may represent a form of abnormal $\mathrm{B}$-cell proliferation that is in some stage of progression from autoreactivity to malignant lymphoma [76].

As in HAE, bradykinin is the primary mediator of swelling in AAE $[12,76]$. Bradykinin in AAE induces the same kind of nonpitting edema without urticaria seen in $\mathrm{HAE}$, recurring at largely unpredictable intervals. The tissue distribution of swelling in AAE may differ somewhat from HAE, with gastrointestinal swelling occurring less frequently and cutaneous swelling occurring more often in the face than in the periphery, with more tongue and uvular involvement [76].

\section{Diagnosis}

AAE may be distinguished from HAE based on age at onset of symptoms and complement protein profile. Unlike HAE, in which symptoms appear in the majority of patients before the age of 20 years [12, 76], AAE generally first manifests in adults after the age of 40 years. Laboratory testing may reveal similarly low values for C1-INH level and functional activity and $\mathrm{C} 4$ antigen. Seventy percent of AAE patients, however, will exhibit a reduced $\mathrm{Clq}$ level, which remains normal in HAE. If Clq is normal, the patient should be tested for the presence of autoantibodies to C1-INH. High titers of antibody confirm a diagnosis of AAE [76]. When C1q is normal and anti-C1INH autoantibodies are not detectable, the acquired na- ture of C1-INH defect is confirmed by the absence of mutation in the C1-INH gene. If AAE is suspected in an elderly patient with angioedema, workup should include protein electrophoresis and plasma/urine analysis for monoclonal proteins, as AAE is closely related to B-cell lymphoma and more frequently to monoclonal gammopathy of undetermined significance (MGUS). Conversely, atypical abdominal pains and edema in lymphoma/ MGUS patients should alert the hematologist to the possibility of C1-INH deficiency.

\section{Treatment}

Replacement of C1-INH is the treatment of choice for acute swelling and has been found to be effective in AAE patients, although the response may change over time [12, 76]. Patients may respond slowly due to their rapid catabolism of C1-INH, necessitating higher-than-usual doses. The presence of autoantibodies to C1-INH progressively renders some patients resistant to this therapy. Icatibant and ecallantide were shown to be effective in nonresponsive patients [78]. These drugs can reverse edematous symptoms through mechanisms that are not dependent on C1-INH activity. Further work will be necessary to better characterize the use of ecallantide and icatibant for acute attacks in AAE patients. When no effective drug is available, supportive therapies that preserve the airway have to be administered in emergency situations.

In HAE patients, attenuated androgens can increase plasma levels of C1-INH, but the same effect may not be seen in AAE patients [76]. As for patients nonresponsive to $\mathrm{C} 1-\mathrm{INH}$, this may be explained by the increased rate of C1-INH catabolism in these patients; the increase in production is unable to compensate for the rate of breakdown.

Antifibrinolytic agents appear to demonstrate better activity in AAE than in HAE [76]. Cicardi and Zanichelli [76] propose that this is due to antiplasmin activity, which is less stable in HAE. Antifibrinolytics are their agents of choice for long-term prophylaxis in AAE.

\section{Summary}

HAE is a widely underrecognized disease resulting in significant disability, pain, morbidity and even mortality. Deficiency of C1-INH results in the unregulated activation of complement, contact and fibrinolytic pathways and the overproduction of bradykinin, which leads to increased vascular permeability and severe edema. Con- 
tinuing research into the disease has recently produced more treatment options and a better understanding of the mechanisms of HAE. The past 5 years have seen new C1INH products become available for this population, as well as agents directed at new targets in the disease process. In addition, the underlying disorders in bradykininmediated angioedema have been better characterized, thus improving management of the related disease of AAE. In the span of a generation, the disease and its treatment have been redefined. These developments are carrying HAE treatment into an ever-evolving future of improved patient care.

\section{Acknowledgments}

The authors wish to thank Judith Devoti, PhD, and Euro RSCG Life Catapult for editorial support in the preparation of the manuscript, which was funded by ViroPharma Inc.

\section{Disclosure Statement}

Dr. Cicardi has served as a speaker for CSL Behring and as a speaker and consultant for Dyax, Pharming and Jerinin/Shire. He has served as a consultant for ViroPharma Inc. (formerly Lev Pharmaceuticals) and received an honorarium from them for writing this article. Dr. Johnston has served as a speaker for Dyax and Shire. He has received research support and speaker honoraria/fees from ViroPharma Inc. in Exton, Pa., and also received an honorarium from them for this article.

\section{References}

1 Osler W: Landmark publication from The American Journal of the Medical Sciences: hereditary angio-neurotic oedema. 1888. Am J Med Sci 2010;339:175-178.

2 Quincke HI: Über akutes umschriebenes Hautödem. Monatsh Prakt Derm 1882;1: 129-131.

-3 Donaldson VH, Evans RR: A biochemical abnormality in hereditary angioneurotic edema: absence of serum inhibitor of $\mathrm{C}^{\prime}$ 1-esterase. Am J Med 1963:35:37-44.

-4 Farkas H, Jakab L, Temesszentandrási G, Visy B, Harmat G, Füst G, Széplaki G, Fekete B, Karádi I, Varga L: Hereditary angioedema: a decade of human C1-inhibitor concentrate therapy. J Allergy Clin Immunol 2007; 120:941-947.

5 Craig T, Riedl M, Dykewicz MS, Gower RG, Baker J, Edelman FJ, Hurewitz D, Jacobs J, Kalfus I: When is prophylaxis for hereditary angioedema necessary? Ann Allergy Asthma Immunol 2009;102:366-372.

6 Frank MM: Hereditary angioedema. J Allergy Clin Immunol 2008;121(suppl 2):S398S401(quiz S419).

7 Bork K, Meng G, Staubach P, Hardt J: Hereditary angioedema: new findings concerning symptoms, affected organs, and course. Am J Med 2006;119:267-274.

8 Bork K, Barnstedt SE: Laryngeal edema and death from asphyxiation after tooth extraction in four patients with hereditary angioedema. J Am Dent Assoc 2003;134:10881094.

9 Bork K, Siedlecki K, Bosch S, Schopf RE, Kreuz W: Asphyxiation by laryngeal edema in patients with hereditary angioedema. Mayo Clin Proc 2000;75:349-354.
10 Lumry WR, Castaldo AJ, Vernon MK, Blaustein MB, Wilson DA, Horn PT: The humanistic burden of hereditary angioedema: impact on health-related quality of life, productivity, and depression. Allergy Asthma Proc 2010;31:407-414.

- 11 Bracho FA: Hereditary angioedema. Curr Opin Hematol 2005;12:493-498.

12 Agostoni A, Aygören-Pürsün E, Binkley KE, Blanch A, Bork K, Bouillet L, Bucher C, Castaldo AJ, Cicardi M, Davis AE, De Carolis C, Drouet C, Duponchel C, Farkas H, Fáy K, Fekete B, Fischer B, Fontana L, Füst G, Giacomelli R, Gröner A, Hack CE, Harmat G, Jakenfelds J, Juers M, Kalmár L, Kaposi PN, Karádi I, Kitzinger A, Kollár T, Kreuz W, Lakatos P, Longhurst HJ, Lopez-Trascasa M, Martinez-Saguer I, Monnier N, Nagy I, Németh E, Nielsen EW, Nuijens JH, O'grady C, Pappalardo E, Penna V, Perricone C, Perricone R, Rauch U, Roche O, Rusicke E, Späth PJ, Szendei G, Takács E, Tordai A, Truedsson L, Varga L, Visy B, Williams K, Zanichelli A, Zingale L: Hereditary and acquired angioedema: problems and progress: proceedings of the third $\mathrm{Cl}$ esterase inhibitor deficiency workshop and beyond. J Allergy Clin Immunol 2004;114(suppl 3):S51-S131.

13 Davis AE III: The pathophysiology of hereditary angioedema. Clin Immunol 2005;114: 3-9.

14 Nussberger J, Cugno M, Amstutz C, Cicardi M, Pellacani A, Agostoni A: Plasma bradykinin in angio-oedema. Lancet 1998;351:16931697.

15 Gompels MM, Lock RJ, Abinun M, Bethune CA, Davies G, Grattan C, Fay AC, Longhurst HJ, Morrison L, Price A, Price M, Watters D: C1 inhibitor deficiency: consensus document. Clin Exp Immunol 2005;139:379-394.
16 Schmaier AH, McCrae KR: The plasma kallikrein-kinin system: its evolution from contact activation. J Thromb Haemost 2007;5: 2323-2329.

17 Schmaier AH: The elusive physiologic role of factor XII. J Clin Invest 2008;118:3006-3009.

18 Shariat-Madar Z, Mahdi F, Schmaier AH: Identification and characterization of prolylcarboxypeptidase as an endothelial cell prekallikrein activator. J Biol Chem 2002; 277:17962-17969.

19 Joseph K, Tholanikunnel BG, Kaplan AP: Heat shock protein 90 catalyzes activation of the prekallikrein-kininogen complex in the absence of factor XII. Proc Natl Acad Sci USA 2002;99:896-900.

20 Joseph K, Tholanikunnel BG, Kaplan AP: Factor XII-independent cleavage of highmolecular-weight kininogen by prekallikrein and inhibition by $\mathrm{C} 1$ inhibitor. J Allergy Clin Immunol 2009;124:143-149.

21 Sainz IM, Pixley RA, Colman RW: Fifty years of research on the plasma kallikreinkinin system: from protein structure and function to cell biology and in-vivo pathophysiology. Thromb Haemost 2007;98:7783.

22 Kleniewski J, Blankenship DT, Cardin AD, Donaldson V: Mechanism of enhanced kinin release from high molecular weight kininogen by plasma kallikrein after its exposure to plasmin. J Lab Clin Med 1992;120:129-139.

23 Bryant JW, Shariat-Madar Z: Human plasma kallikrein-kinin system: physiological and biochemical parameters. Cardiovasc Hematol Agents Med Chem 2009;7:234-250.

24 Weis M: Clinical review of hereditary angioedema: diagnosis and management. Postgrad Med 2009;121:113-120. 
25 Cugno M, Cicardi M, Bottasso B, Coppola R, Paonessa R, Mannucci PM, Agostoni A: Activation of the coagulation cascade in C1-inhibitor deficiencies. Blood 1997;89:32133218.

26 Moreau ME, Garbacki N, Molinaro G, Brown NJ, Marceau F, Adam A: The kallikrein-kinin system: current and future pharmacological targets. J Pharmacol Sci 2005; 99:6-38.

-27 Han ED, MacFarlane RC, Mulligan AN Scafidi J, Davis AE III: Increased vascular permeability in $\mathrm{C} 1$ inhibitor-deficient mice mediated by the bradykinin type 2 receptor. J Clin Invest 2002;109:1057-1063.

28 Kaplan AP, Silverberg M: The coagulationkinin pathway of human plasma. Blood 1987; 70:1-15.

-29 Golias Ch, Charalabopoulos A, Stagikas D, Charalabopoulos K, Batistatou A: The kinin system-bradykinin: biological effects and clinical implications. Multiple role of the kinin system-bradykinin. Hippokratia 2007; 11:124-128

30 Nzeako UC, Frigas E, Tremaine WJ: Hereditary angioedema: a broad review for clinicians. Arch Intern Med 2001;161:2417-2429.

- 31 Duan QL, Nikpoor B, Dube MP, Molinaro G, Meijer IA, Dion P, Rochefort D, Saint-Onge J, Flury L, Brown NJ, Gainer JV, Rouleau JL, Agostoni A, Cugno M, Simon P, Clavel P, Potier J, Wehbe B, Benarbia S, Marc-Aurele J, Chanard J, Foroud T, Adam A, Rouleau GA: A variant in XPNPEP2 is associated with angioedema induced by angiotensin I-converting enzyme inhibitors. Am J Hum Genet 2005; 77:617-626.

- 32 Leeb-Lundberg, LM, Marceau F, Müller-Esterl W, Pettibone DJ, Zuraw BL: International union of pharmacology. XLV. Classification of the kinin receptor family: from molecular mechanisms to pathophysiological consequences. Pharmacol Rev 2005;57:2777.

33 Zuraw BL: Clinical practice. Hereditary angioedema. N Engl J Med 2008;359:10271036.

34 Ferraro MF, Moreno AS, Castelli EC, Donadi EA, Palma MS, Arcuri HA, Lange AP, Bork K, Sarti W, Arruda LK: A single nucelotide deletion at the $\mathrm{C} 1$ inhibitor gene as the cause of hereditary angioedema: insights from a Brazilian family. Allergy, 2011, E-pub ahead of print.

-35 Bossi F, Fischetti F, Regoli D, Durigutto P, Frossi B, Gobeil F Jr, Ghebrehiwet B, Peerschke EI, Cicardi M, Tedesco F: Novel pathogenic mechanism and therapeutic approaches to angioedema associated with $\mathrm{C} 1$ inhibitor deficiency. J Allergy Clin Immunol 2009;124:1303-1310.e4.

36 Bouillet L, Mannic T, Arboleas M, Subileau M, Massot C, Drouet C, Huber P, Vilgrain I: Hereditary angioedema: key role for kallikrein and bradykinin in vascular endothelial-cadherin cleavage and edema formation. J Allergy Clin Immunol 2011;128:232-234.
Shoemaker LR, Schurman SJ, Donaldson VH, Davis AE III: Hereditary angioneurotic oedema: characterization of plasma kinin and vascular permeability-enhancing activities. Clin Exp Immunol 1994;95:22-28.

38 Han ED, McFarlane RC, Mulligan AN, Scafidi J, Davis AE III: Increased vascular permeability in $\mathrm{C} 1$ inhibitor deficient mice mediated by the bradykinin type 2 receptor. J Clin Invest 2002;109:1057-1063.

39 De Backer AI, De Schepper AM, Vandevenne JE, Schoeters P, Michielsen P, Stevens WJ: CT of angioedema of the small bowel. AJR Am J Roentgenol 2001;176:649-652.

40 Prematta MJ, Kemp JG, Gibbs JG, Mende C, Rhoads C, Craig TJ: Frequency, timing, and type of prodromal symptoms associated with hereditary angioedema attacks. Allergy Asthma Proc 2009;30:506-511.

41 Farkas H, Harmat G, Kaposi PN, Karádi I, Fekete B, Füst G, Fáy K, Vass A, Varga L: Ultrasonography in the diagnosis and monitoring of ascites in acute abdominal attacks of hereditary angioneurotic oedema. Eur J Gastroenterol Hepatol 2001;13:1225-1230.

42 Pedrosa M, Caballero T, Gomez-Traseira C, Olveira A, López-Serrano C: Usefulness of abdominal ultrasonography in the follow-up of patients with hereditary C1-inhibitor deficiency. Ann Allergy Asthma Immunol 2009; 102:483-486.

43 Bowen T, Cicardi M, Farkas H, Bork K, Longhurst HJ, Zuraw B, Aygoeren-Pürsün E, Craig T, Binkley K, Hebert J, Ritchie B, Bouillet L, Betschel S, Cogar D, Dean J, Devaraj $\mathrm{R}$, Hamed A, Kamra P, Keith PK, Lacuesta G, Leith E, Lyons H, Mace S, Mako B, Neurath D, Poon MC, Rivard GE, Schellenberg R, Rowan D, Rowe A, Stark D, Sur S, Tsai E, Warrington R, Waserman S, Ameratunga R, Bernstein J, Björkander J, Brosz K, Brosz J, Bygum A, Caballero T, Frank M, Fust G, Harmat G, Kanani A, Kreuz W, Levi M, Li H, Martinez-Saguer I, Moldovan D, Nagy I, Nielsen EW, Nordenfelt P, Reshef A, Rusicke E, Smith-Foltz S, Späth P, Varga L, Xiang ZY: 2010 International Consensus Algorithm for the Diagnosis, Therapy and Management of Hereditary Angioedema. Allergy Asthma Clin Immunol 2010;6:24.

44 Weiler CR, van Dellen RG: Genetic test indications and interpretations in patients with hereditary angioedema. Mayo Clin Proc 2006;81:958-972.

45 Zuraw BL: Novel therapies for hereditary angioedema. Immunol Allergy Clin North Am 2006;26:691-708.

46 Cicardi M, Zingale L: How do we treat patients with hereditary angioedema. Transfus Apher Sci 2003;29:221-227.

47 CSL Behring: CSL Behring receives national marketing authorization of Berinert in Israel. The US Hereditary Angioedema Association, 2011. http://www.haea.org/news/cslbehring-receives-national-marketing-authorization-of-berinert-in-israel (accessed July 18, 2011).
48 Berinert package insert. Kankakee, CSL Behring LLC, 2009.

49 Craig TJ, Levy RJ, Wasserman RL, Bewtra AK, Hurewitz D, Obtułowicz K, Reshef A, Ritchie B, Moldovan D, Shirov T, GrivchevaPanovska V, Kiessling PC, Keinecke HO, Bernstein JA: Efficacy of human C1 esterase inhibitor concentrate compared with placebo in acute hereditary angioedema attacks. J Allergy Clin Immunol 2009;124:801-808.

50 Ruconest summary of product characteristics. Leiden, Pharming Group N.V., 2010.

51 Cicardi M, Banerji A, Bracho F, Malbrán A, Rosenkranz B, Riedl M, Bork K, Lumry W, Aberer W, Bier H, Bas M, Greve J, Hoffmann TK, Farkas H, Reshef A, Ritchie B, Yang W, Grabbe J, Kivity S, Kreuz W, Levy RJ, Luger T, Obtulowicz K, Schmid-Grendelmeier P, Bull C, Sitkauskiene B, Smith WB, Toubi E, Werner S, Anné S, Björkander J, Bouillet L, Cillari E, Hurewitz D, Jacobson KW, Katelaris $\mathrm{CH}$, Maurer M, Merk H, Bernstein JA, Feighery C, Floccard B, Gleich G, Hébert J, Kaatz M, Keith P, Kirkpatrick CH, Langton D, Martin L, Pichler C, Resnick D, Wombolt D, Fernández Romero DS, Zanichelli A, Arcoleo F, Knolle J, Kravec I, Dong L, Zimmermann J, Rosen K, Fan WT: Icatibant, a new bradykinin-receptor antagonist, in hereditary angioedema. N Engl J Med 2010;363: 532-541.

52 Lumry WR, Li HH, Levy RJ, Potter PC, Farkas H, Reshef A, et al: Results from FAST-3: a phase III randomized, double-blind, placebo-controlled, multicenter study of subcutaneous icatibant in patients with acute hereditary angioedema (HAE) attacks. Program and abstracts of AAAAI, San Francisco, 2011, abstract L2.

53 Firazyr summary of product characteristics. Berlin, Jerini AG, 2008.

54 ViroPharma Inc: ViroPharma's Cinryze ${ }^{\circledR}$ (C1 inhibitor [human]) granted European marketing authorization for hereditary angioedema (HAE) (news release). Exton, ViroPharma Inc, 2011. http://ir.viropharma. com/releasedetail.cfm?ReleaseID $=585060$ (accessed July 18, 2011).

55 Zuraw BL, Busse PJ, White M, Jacobs J, Lumry W, Baker J, Craig T, Grant JA, Hurewitz D, Bielory L, Cartwright WE, Koleilat M, Ryan W, Schaefer O, Manning M, Patel P, Bernstein JA, Friedman RA, Wilkinson R, Tanner D, Kohler G, Gunther G, Levy R, McClellan J, Redhead J, Guss D, Heyman E, Blumenstein BA, Kalfus I, Frank MM. Nanofiltered $\mathrm{C} 1$ inhibitor concentrate for treatment of hereditary angioedema. N Engl J Med 2010; 363:513-522.

56 Kalbitor package insert. Cambridge, Dyax Corp, 2009.

57 Gelfand JA, Sherins RJ, Alling DW, Frank MM: Treatment of hereditary angioedema with danazol. Reversal of clinical and biochemical abnormalities. N Engl J Med 1976; 295:1444-1448. 
58 Sheffer AL, Fearon DT, Austen KF: Methyltestosterone therapy in hereditary angioedema. Ann Intern Med 1977;86:306-308.

- 59 Hosea SW, Santaella ML, Brown EJ, Berger M, Katusha K, Frank MM: Long-term therapy of hereditary angioedema with danazol. Ann Intern Med 1980;93:809-812.

60 Cicardi M, Bergamaschini L, Cugno M, Hack E, Agostoni G, Agostoni A: Long-term treatment of hereditary angioedema with attenuated androgens: a survey of a 13-year experience. J Allergy Clin Immunol 1991;87: 768-773.

-61 Sheffer AL, Fearon DT, Austen KF: Hereditary angioedema: a decade of management with stanozolol. J Allergy Clin Immunol 1987;80:855-860.

62 Bork K, Bygum A, Hardt J: Benefits and risks of danazol in hereditary angioedema: a longterm survey of 118 patients. Ann Allergy Asthma Immunol 2008;100:153-161.

-63 Fust G, Farkas H, Csuka D, Varga L, Bork K: Long-term efficacy of danazol treatment in hereditary angioedema. Eur J Clin Invest 2010;41:256-262.

64 Craig TJ: Appraisal of danazol prophylaxis for hereditary angioedema. Allergy Asthma Proc 2008;29:225-231.

65 Sloane DE, Lee CW, Sheffer AL: Hereditary angioedema: Safety of long-term stanozolol therapy. J Allergy Clin Immunol 2007;120: 654-658.
66 Cicardi M, Castelli R, Zingale LC, Agostoni A: Side effects of long-term prophylaxis with attenuated androgens in hereditary angioedema: comparison of treated and untreated patients. J Allergy Clin Immunol 1997;99: 194-196.

-67 Bork K, Pitton M, Harten P, Koch P: Hepatocellular adenomas in patients taking danazol for hereditary angio-oedema. Lancet 1999; 353:1066-1067.

68 Bork K, Schneiders V: Danazol-induced hepatocellular adenoma in patients with hereditary angio-oedema. J Hepatol 2002;36:707709.

69 Crampon D, Barnoud R, Durand M, Ponard D, Jacquot C, Sotto JJ, Letoublon C, Zarski JP: Danazol therapy: an unusual aetiology of hepatocellular carcinoma (letter). J Hepatol 1998;29:1035-1036.

70 Veit V, Hardwigsen J, Bernit E, Gachon J, Kaplanski G, Schlienger JL: Traitment par danazol, une étiologie exceptionnelle d'hépatocarcinome: à propos d'une observation. Rev Méd Interne 1999;20:634S.

71 Helsing P, Nielsen EW: Hepatocellular focal nodular hyperplasia after danazol treatment for hereditary angio-oedema. Acta Derm Venereol 2006;86:272-273.
72 Szeplaki G, Varga L, Valentin S, Kleiber M, Karadi I, Romics L, Füst G, Farkas H: Adverse effects of danazol prophylaxis on the lipid profiles of patients with hereditary angioedema. J Allergy Clin Immunol 2005;115: 864-869.

73 Szegedi R, Szeplaki G, Varga L, Prohaszka Z, Szeplaki Z, Karadi I, Füst G, Farkas H: Longterm danazol prophylaxis does not lead to increased carotid intima-media thickness in hereditary angioedema patients. Atherosclerosis 2008;198:184-191.

74 Birjmohun RS, Kees Hovingh G, Stroes ES, Hofstra JJ, Dallinga-Thie GM, Meijers JC, Kastelein JJ, Levi M: Effects of short-term and long-term danazol treatment on lipoproteins, coagulation, and progression of atherosclerosis: two clinical trials in healthy volunteers and patients with hereditary angioedema. Clin Ther 2008;30:2314-2323.

75 Cinryze package insert. Exton, ViroPharma Inc, 2011.

76 Cicardi M, Zanichelli A: Acquired angioedema. Allergy Asthma Clin Immunol 2010;6: 14.

77 Markovic SN, Inwards DJ, Frigas EA, Phyliky RP: Acquired C1 esterase inhibitor deficiency. Ann Intern Med 2000;132:144-150.

-78 Zanichelli A, Badini M, Nataloni I, Montano $\mathrm{N}$, Cicardi M: Treatment of acquired angioedema with icatibant: a case report. Intern Emerg Med 2011;6:279-280. 